\title{
Practice and Thinking on the Incentive Mechanism of Physical Education in Colleges and Universities
}

\author{
Ding Peng ${ }^{1,2}$, Wen $\mathrm{Li}^{3}$ \\ ${ }^{1}$ East China Jiaotong University, China \\ ${ }^{2}$ Jiangxi Vocation College of Ahead Software, China \\ ${ }^{3}$ Institute of Technology, East China Jiaotong University, China
}

Keywords: Physical education in colleges and universities, Incentive mechanism, Practice

\begin{abstract}
The incentive mechanism as an important mean in the management, it's specific implementation has a variety of ways, such as objective incentive, emotional incentive, ideal incentive and so on. This paper describes the main methods to implement the incentive mechanism of physical education in colleges and universities from the important significance of the incentive mechanism in the process of teaching, and puts forward the further thinking about the incentive mechanism in order to provide a reference value for the benign development of physical education management.

The incentive, in the literal sense as to inspire and encourage, the teaching of physical education in colleges and universities using the incentive mechanism is to stimulate students' learning enthusiasm by encouraging, to encourage students to actively participate in physical education, the purpose is to change the learning from passive to active, and to stimulate their creativity in the process of participation in learning.
\end{abstract}

\section{The important significance of incentive mechanism in teaching}

The incentive in college physical education mainly refers to how to adopt the ways and methods of incentive to encourage students to participate in sports activities and physical exercises actively, actively and creatively. In physical education, it is very obvious that it is necessary to form an incentive mechanism correctly, which can be reflected in the following points:

\subsection{The incentive mechanism of physical education in colleges and universities helps to enhance the students' desire for knowledge}

The desire for knowledge is the primary condition of students' autonomous learning, in order to enable students to learn independently and voluntarily, must adopt the incentive mechanism, to arouse students' curiosity and desire for knowledge, to motivate them to form their own learning objectives and to develop their own learning plan, so as to achieve the effect of learning to play the subjective role.

\subsection{The incentive mechanism of physical education in colleges and universities helps to clear the teaching objectives and improve the teaching process}

In the process of physical education, through the establishment of an effective incentive mechanism, according to the different situation of different students, to establish specific teaching objectives, to take different incentive ways for different students, to carry out a different degree of incentive to them, to encourage every student to move forward to his own goal.

\subsection{The incentive mechanism of physical education in colleges and universities is beneficial to form good relationship between teachers and students}

Praise and affirmation are effective ways to promote the progress of the relationship between teachers and students, which can increase teachers' intimacy and students' emotional dependence on 
teachers, and can help teachers and students to respect each other and trust each other.

\subsection{The incentive mechanism of physical education in colleges and universities helps students to form a correct attitude of learning and a positive attitude to life}

For college students, learning is not limited to the mastery of book knowledge, college students need to develop the correct habit of physical exercise. The incentive mechanism in physical education can not only make students interested in sports and desire for knowledge, but also can cultivate students' correct and positive attitude towards life, to make students develop good habits of physical exercise and benefit for whole life.

\subsection{The incentive mechanism in physical education helps the students' mental health}

In colleges and universities, many students do not like physical education, because the intensity of training is great, it not only has the test of physical ability, but also needs students to have good psychological quality. However, using the incentive mechanism, can make students feel the benefits brought by sports in physical education class, and guide students to form a correct and positive psychological attitude.

\subsection{The incentive mechanism in physical education helps to realize the all-round development of people}

As is known to all that the sports ability of students in colleges and universities is not high, on the one hand, college students need to master certain professional knowledge and skills, on the other hand, all-round development is the basic requirement for college students, meanwhile college students in the learning of professional knowledge, but also should pay attention to the improvement of sports ability. The use of incentive mechanism in the process of teaching will help to stimulate the enthusiasm and interest of college students in sports activities and guide the all-round development of students.

\section{The main methods to implement incentive mechanism in the teaching of physical education in colleges and universities}

\subsection{Objective incentive mechanism}

This incentive mechanism mainly requires students to formulate a learning goal, and to stimulate students' learning enthusiasm and learning potential through the internal driving force for learning purpose. The practice in the teaching of physical education is also very common, such as the project of physical fitness test "crunches", to test the situation of completion and collect the data for the students before the exam, in the formal examination, to make the test goals slightly higher than the average level, through the the teaching work which have clear objectives and reasonable plan with a certain period of time, almost all the students are higher than the average level, the performance has been greatly improved, this is the role of objective incentive in teaching.

\subsection{Incentive mechanism of example}

The example in the incentive mechanism of example can be a teacher or an excellent student representative, which is also called emotional incentive, is mainly to motivate the students to study actively by the teachers' moral and professional abilities. The survey showed that more than $90 \%$ of the students were eager for teachers to carry out their own teaching activities and teach them with demonstrative and interactive methods. Physical education teachers themselves have high sports ability and professional level, teachers can use this point to interact with students, which can produce good incentives for students.

\subsection{Competitive incentive mechanism}

This incentive mechanism refers to the use of students' ambition in teaching, focusing on the teaching objectives and contents, to organize the competitive incentive mechanism in the form the game, mainly has two forms of team tournament and individual race, among of them, the effect of 
team tournament is the best. For example, in the process of classroom teaching, carrying out unified teaching and group competition, to encourage students to cooperate with each other and mutual assistance between each other with team spirit and team pride, to make students play their own skills and abilities fully and unconsciously in these kind of games. In addition, we can also take class as a unit to play friendly matches, which can not only stimulate students' initiative learning ability and enhance teaching effect by competition, but also encourage students to form good teamwork spirit and inspire students' sense of collective honor.

\subsection{Participatory incentive mechanism}

Participatory incentive mainly refers to the cooperation of teaching and learning to enable students to actively participate in the process of teaching, to fully stimulate the students' subjective initiative. The specific practice method is to let the students actively develop the teaching plans, learning methods and learning goals, to enable students to participate in the preparation of teaching activities, according to their own situation, to actively develop their own learning content and objectives, to encourage students to put forward their views and suggestions and questions to the teachers in class and after class, to form democratic teaching atmosphere, to let the students who have better learning effect demonstrate and share learning experiences in the process of teaching, to enable students to effectively participate in the teaching process, to stimulate students' initiative exploration willingness and spirit for the content in the classroom.

\subsection{Physical incentive mechanism}

The physical incentive method is adopted by many schools, is mainly refers to give material rewards to the students who perform better in the classroom or in the examination. Under this incentive mechanism, need to pay attention to grasp the degree, to avoid students psychological dependence on the prizes, who lost the reward will be easy to slack and lost the power, so this incentive mechanism must be used in conjunction with other incentive mechanism, and need to pay attention that must be in the process of teaching, which is beneficial to students' interest in learning and learning content prizes.

\subsection{Speech incentive mechanism}

This incentive mechanism mainly refers to teachers' encouragement and affirmation that using complimentary language to encourage and affirm students according to students' character and classroom performance in accordance with teaching contents in the process of teaching, so as to stimulate their interest in learning and enthusiasm for learning. Speech includes written praise and oral praise, the main purpose is to stimulate students' sense of achievement, to increase students' motivation to study, and to give students certain confidence. In the process of physical education, oral commendation and compliment are mainly used. Teachers should pay attention to the diversity of language and can't give the same verbal encouragement to all students, which are not sincere, and are not able to make students actively accept and become interested in.

\section{Thinking on incentive mechanism in physical education}

\subsection{Guidance of incentive mechanism}

The difference of methods, contents and usage for incentive mechanism will have a direct impact on teaching effect, and even have different effects on the development of education. The guidance of the incentive mechanism determines that teachers should correctly use the incentive methods in the course of physical education and ensure the completion of the correct teaching objectives.

\subsection{Pertinence of incentive mechanism}

Incentive can not be applied to students who are in different situations, teachers should according to the differences of individual differences and teaching contents to carry out the incentive with different ways and different degrees. One is the individual differences of students, such as character characteristics, learning ability and so on, which determines teachers what incentive methods should 
be adopted and how to motivate them. Another is according to different teaching contents, teachers should adopt incentive methods accordingly, for example, teaching contents that are difficult for students to accept should be induced and encouraged to stimulate students' interest in learning.

\subsection{Continuity of incentive mechanism}

Incentive must be continued, then can continue to mobilize the students' initiative in self-study. Intermittent incentives can not only achieve the enhancement of teaching effect, but may cause students' slack psychology, and create a moods of distrust to teachers, and affect the harmonious relationship between teachers and students.

\subsection{Timing of incentive mechanism}

The completion of everything must be given a certain time, and the implementation of the incentive mechanism is the same. The timing of the incentive mechanism is very particular, and the same incentives at different times will produce different effects. For example, it is very different to encourage students when they get certain grades, and encourage students when their grades are not ideal. Therefore, incentives must be taken at the best time, only then can produce the maximum effect.

\section{Conclusion}

In a word, the first starting point of the incentive mechanism is to take care of the students. Love is the teacher's love and protection to the students. Love refers to the teacher to the students not be to favour one more than another, should be equal. Protection refers to the protection of teachers' self-esteem to students, many colleges and universities exist the phenomenon of corporal punishment in the process of physical education, thinks that strict teachers can teach good students, although it is possible to achieve the purpose of teaching for a moment, makes students have tired psychology, has no interest for sports activities in outside class. Therefore, teachers should not only realize the effect of teaching, but also take into account the students' emotions. Of course, the students should be encouraged in different degrees and different forms according to the individual differences of the students, so they can not be monotonous, so as to avoid the students' slack mentality. The starting point of incentive mechanism in college physical education is to enable students to complete their learning objectives and maximize the teaching effect, so we must take students' development as the fundamental starting point. In the course of teaching, students should be equal and impartial. In addition, teachers should implement incentive mechanism specifically, aiming at students' individual differences, and should take students as center and take the people as orient, so that students can achieve self-improvement and self-development.

\section{References}

[1] Yan Ji. Physical and thinking on the incentive mechanism for the physical education in colleges and universities [J]. Industry and Technology Forum, 2015, 06.

[2] Lei Yu. Research on the incentive mechanism of physical education in colleges and universities under the new era [J]. Shandong Social Sciences, 2015, 12.

[3] Gongxin Chen. Practice and thinking on the incentive mechanism of physical education in colleges and universities [J].Modern communication, 2017, 06.

[4] Jingyi Zhang. The use of incentive language in physical education in colleges and universities under the incentive mechanism [J]. Western leather, 2016, 10.

[5] Xinjia He, Yefeng Wang. Research on the construction of incentive mechanism for physical education in general colleges and universities [J]. Journal of Hotan Teachers College, 2010, 03. 